\title{
Entry, Progression, Exit, and Service Provision for Survivors of Sex Trafficking: Implications for Effective Interventions
}

\author{
Gretchen Clark Hammond • Mandy McGlone
}

Published online: 22 March 2014

(C) Springer International Publishing 2014

\begin{abstract}
Human trafficking continues to evolve as an issue of importance in many communities. The proliferation of human trafficking is worldwide and involves forced labor, often of young persons. This literature review focuses on the form of human trafficking that involves sex trafficking and prostitution. Terms also used to describe this situation include domestic minor sex trafficking (DMST), sex work, child sexual exploitation, and prostitution. This paper focuses on four points of interest: (1) the process of entry into sex trafficking, (2) the progression once one is trafficked/prostituted, (3) the process for exiting, and (4) services for victims/ survivors. The paper concludes with recommendations for service provision, including the arenas of healthcare, social services, child welfare, and law enforcement.
\end{abstract}

Keywords Human trafficking · Sex trafficking · Survivors · Traffickers · Victims

\section{Human Trafficking Overview}

Human trafficking is an issue of importance in many communities and is evolving in public awareness and response. Major forms of human trafficking include forced or bonded labor, debt bondage and involuntary domestic servitude, forced child labor, child soldiers, sex trafficking and prostitution, commercial sexual exploitation of children, and child sex tourism (US Department of State 2008, 2012). Labor exploitation is part of a global market of commodities (i.e., grains, coffee, cocoa, sugar, cotton, and gems) and is seen in construction, manufacturing, mining, and agriculture. Sexual exploitation

G. C. Hammond $(\bowtie) \cdot$ M. McGlone

Managing Partners, Mighty Crow Media, LLC,

13559 Capetown Ave., Pickerington, OH 43147, USA

e-mail: Gretchen.hammond@mightycrowmedia.com

M. McGlone

e-mail: Mandy.mcglone@mightycrowmedia.com and sex trafficking are also part of a global market of commodities and are considered a modern form of slavery (Alvarez and Alessi 2012). Human trafficking is a "multidimensional threat" to society, depriving people of human rights and freedoms, increasing global health risks, and fueling the growth of organized crime (US Department of State 2008, p. 5). People may fall victim to trafficking for reasons that include wanting a better life or discovering a promising job opportunity (US Department of State 2012). Children are especially at risk to be trafficked because of their vulnerabilities: their small size, their naïve nature, and their ability to be intimidated (Alvarez and Alessi 2012). Traffickers recognize these vulnerabilities and prey upon these children with coercive techniques and violence.

Human trafficking is an extensive topic and is worthy of significant discussion. This article will focus on sex trafficking exclusively, as it "comprises a significant portion of overall trafficking and the majority of transnational modern-day slavery" (US Department of State 2008, p. 23). The purpose of this article is to develop an understanding of the how of human trafficking - how victims are lured in (entry), how they are kept in (progression), how they are able to exit, and how they might be able to heal with help from service providers - in an effort to improve community strategies geared toward prevention and intervention. Implications for social workers, assisting with the development and implementation of community responses for survivors of trafficking, are provided. Organizations working on this important global issue are included as a supplement to the final section on service provision.

\section{Sex Trafficking Overview}

Sex trafficking, first and foremost, is a business that consists of the persons trafficked (the victims), the consumers (buyers, "Johns"), and the persons who procure the victims and supply them to the consumers (the traffickers) (Williamson et al. 2012). There are child and adult sex trafficking victims, delineated mostly by age of entry. Forms of 
sex trafficking include child sex tourism (CST) and commercial sexual exploitation of children or domestic minor sex trafficking (DMST), and prostitution. CST involves persons who travel from their home country to another country to engage in sex acts with children. Oftentimes, these destinations are in countries where this type of activity is less regulated or policed (US Department of State 2008). DMST involves commercial sexual abuse of children through buying, selling, or trading their sexual services through prostitution, pornography, stripping, escort services, and other sexual services (Kotrla 2010). Many children exploited for commercial sex are trapped in prostitution as they age into adolescence and adulthood (US Department of State 2008; Kotrla 2010).

Determining the incidence and prevalence of sex trafficking is complex. Estimates range from 1,400 to 600,000 persons to two million worldwide (US Department of State 2008; 2012; ICF International 2007). Stansky and Finkelhor (2008) caution that these numbers are essentially a guess or extrapolation because of the lack of credible methods for estimating figures and the varying definitions for classifying someone as "trafficked." Data from others, such as social service, municipal and domestic courts, or child welfare providers, often does not include trafficking as a variable, making this information less precise. Arrest reports and criminal justice filings provide the majority of the data that is included in many published reports. Despite these challenges, researchers, governmental organizations, and service providers are working toward better estimates through centralized data collection, operationalized definitions, and collaboration among systems. These issues are not unique to one state, country, or region of the world, as this issue is hidden and difficult to track by design of those who traffick and exploit.

\section{Victims of Sex Trafficking}

A necessary first step toward an informed discussion about a topic is an understanding of the terminology being used. Persons involved in sex trafficking are victimized, coerced, and manipulated. The classification of child and adult victims can vary by the definitions within certain statutes (i.e., The Trafficking Victims Protection Act of 2000) and can become challenging when trying to determine elements like force, fraud, or coercion, as well as time of entry versus time of identification (Reid 2012). The type of sex work involved is a demarcation that is less about status as a victim or survivor and more about a classification of activity. What was once labeled "prostitution" may be more accurately "sex trafficking" as the term "trafficked" emerges in the consciousness of survivors and greater society. One must question the assumptions behind the terms for adult sex workers as "prostitute" or "solicitation" as potentially misplaced since many of these women entered into this life as children and adolescents through manipulation and force. Therefore, sex trafficking and prostitution will be used as interchangeable terms in this article to emphasize the blurred lines between these categories and the misconceptions assigned to adult victims as willing participants in "the oldest profession."

\section{The Process of Entry}

The process of entry into sex trafficking is an area of research that is examined across disciplines of social work, sociology, psychology, nursing, criminal justice, and others. Explanations of this process focus on risk factors that contribute to entrance into sex trafficking, as well as relational and environmental factors. Describing the pathway into sex trafficking is an essential feature for prevention strategies, as well as being informative for intervention strategies.

\section{Risk Factors}

Victims of sex trafficking are often young (ranging from 10 to 17 years old at the time of entry) and have several adverse childhood experiences in common, including sexual abuse, physical abuse, neglect, and running away from home (Kotrla 2010; Williamson et al. 2012; Wilson and Dalton 2008; Nixon et al. 2002; US Department of State 2008; 2012). There are identified risk factors that make someone more vulnerable to victimization, including negative family dynamics, lower intellectual functioning, poor school success, inadequate social skills, and histories of physical, sexual, and emotional abuse, and neglect (Benoit and Millar 2001; Kramer and Berg 2003; Newby and McGuinness 2012; Nixon, Nixon, et al. 2002; Reid 2012; Twill et al. 2010).

Child welfare involvement is also common in the experience of victims of sex trafficking. Nixon, et al. (2002), found that $64 \%$ of women involved in sex trafficking had been in the child welfare system as children, including foster and group homes, often for many years. Sexual abuse in the home or home setting increases the chance that a youth will run away. Runaways, homeless children, kidnapped children, or children in or leaving foster care are at elevated risk of forced prostitution and trafficking (Fong and Cardoso 2010; Twill et al. 2010).

\section{Pathways}

There are some common pathways into trafficking identified in the research. Adverse experiences, including abuse and violence, victimization, and manipulation, are present within each one. The pathways into trafficking depend upon certain vulnerabilities being present, which become risk factors. At a basic human needs level, these factors include feeling unsafe (due to abuse and violence), having an unstable living situation that prompts a child to run away, or being without caring adult supervision. Childhood sexual victimization plays a 
significant role as an antecedent into sex trafficking (Hossain et al. 2010; Nadon et al. 1998; Williamson et al. 2012), sometimes doubling the odds of entering (McClanahan et al. 1999). The experience of rape (sexual victimization) reveals a relationship with entry into trafficking as well (Campbell et al. 2003). Most survivors (75\%) stated they felt their engagement in prostitution was related to the rape(s), with the hopes of regaining some control over their bodies by limiting access and exchanging sex for money (Campbell et al. 2003). Kramer and Berg (2003) found that the experience of at least one childhood risk factor (sexual abuse, physical abuse, parental drug abuse) significantly increased the rate for entry into prostitution relative to those experiencing no risks.

Additional risk factors that come with adverse situations include exposure to alcohol and drugs, proximity to violent and dangerous people, and difficulty focusing on and behaving in school. These factors make a child more susceptible to victimization (Kotrla 2010; Newby and McGuinness 2012; Sabella 2011; Williamson et al. 2012). Race and gender are also vulnerabilities, in that most victims of sex trafficking are female and are often marginalized persons (Kramer and Berg 2003; Rand 2009; US Department of State 2012). Reid's (2012) Framework of Age-Graded Theory of Informal Social Control Applied to Vulnerability in Sex Trafficking provides a detailed and contextualized model for understanding the factors related to pathways. This framework considers specific types of victims and targeted prevention and intervention efforts.

Traffickers exploit these risk factors as they recruit children, adolescents, and adults (Sabella 2011). Their techniques include (a) grooming or "finesse pimping," wherein a young girl is lured into a situation where she appears to be making her own decisions about her life; (b) "bait and switch," wherein an attractive opportunity is presented in order to gain trust and hope only to later change the situation upon entry; and (c) "guerilla pimping," wherein the trafficker recruits through the use of threat, physical violence, or other forms of coercion (Ohio Trafficking in Persons Report and Research and Analysis Sub-Committee 2010; Williamson and Prior 2009). These techniques all involve a relationship of some sort, and thus, the relational aspects of trafficking play into these risk factors and are discussed in the next section.

\section{Relational Context of Entry}

The relationships between victims and sex traffickers are complex, as traffickers often engage potential victims through relational means - using expressions of care and concern, love, and attention (Nadon et al. 1998). Based on the literature, one can assume that those victimized are often runaway or atrisk youth who are in need of shelter, food, clothing, and other basic needs. It is likely that they were neglected and/or abused and are seeking a connection or attachment to a caring individual. Twill et al. (2010) found "Female adolescents who were engaged in prostitution were also likely to have been involved in a number of short-term relationships that were generally exploitative...girls turned to these relationships, in part, due to a lack of appropriate social skills" (p. 190). At the core of this process is a need for emotional and physical safety, which the trafficker may appear to provide. Thus, the juvenile enters this relationship believing they will be safe or at least "OK." Relationships quickly progress from "friendship" to sexual, then to "business."

Traffickers use relationships within their network, using their victims to assist them in recruiting, retention, and other aspects of the business (Wilson and Dalton 2008). Once someone is lured in, they must be detained (Zimmerman et al. 2011). Therefore, traffickers work to control their victims through various means. They use emotional, physical and sexual violence, and economic abuse to keep victims in their custody. Victims are monitored closely by the trafficker and his associates, making it nearly impossible to escape. Traffickers also use isolation from family, friends, and the public to limit the victim's ability to build supportive social networks, as well as her ability to be recognized and rescued (Dovydaitis 2010). Another sinister control tactic employed by traffickers and pimps is to purposely impregnate the female victim, further tightening his grip upon her. The trafficker is now the father of the victim's child and will use that child as a means to keep her connected to him through threats and economic means (Dovydaitis 2010; Wilson and Dalton 2008).

Traffickers may utilize a process of reidentification of their victims, adding another layer of control. Not only is the trafficker controlling where the victim is located, what she does, and who she sees, he also controls who she is as a person. Wilson and Dalton (2008) found "sex traffickers often gave their juvenile victims new identities and taught them never to give their real name or age to police" (p. 303). Removal of identity documents such as a driver's license further limits a victim's ability to escape the situation, as she is rendered nameless and faceless. These efforts have one purpose: to remain unseen. This approach to the business affords the trafficker more anonymity and a cloak of invisibility to those who may be watching. It is necessary to recognize that traffickers come from a broad spectrum of society and can be known professionals (i.e., doctors, businessmen, etc.) who remain under the radar of detection. Their operations are designed to be sophisticated and elusive (Williamson et al. 2012).

Thus, the process of entry is calculated in favor of the victim remaining in the hands of the person(s) who lured and/or abducted her. Once inside this world, it becomes increasingly difficult to escape. The victimization, isolation, reidentification, and exposure to violence, danger, and drugs further entrench the child, adolescent, or adult who is sex trafficked. The following section discusses what may occur once someone has entered and become involved. 


\section{Progression}

Once a girl/adolescent/woman is trafficked, there is an unknown amount of time in which she remains in this situation (Rand 2009; Zimmerman et al. 2011). In this stage of the human trafficking process, victims are detained, exploited, and often retrafficked (Zimmerman et al. 2011). Williamson and Folaron (2003) propose five developmental phases of prostitution based on their research with adult women who experienced sex trafficking. These developmental stages provide insight into the experience of those living within this experience of sex trafficking and amplify the reality that sex trafficking is a more complicated issue beyond entry and exit. These stages provide insight into the individual's possible motivations for remaining or exiting and therefore assist providers in planning an intervention. Common to all phases is the desire for "something better" for themselves, which must be remembered by those working to intervene (Williamson and Folaron 2003). These stages are summarized in Table 1.

As Table 1 demonstrates, diversity exists within these stages of progression within sex trafficking/prostitution. One can posit that there are different motivations at each stage that will entice a woman into exiting. When one is in the earlier stages and prostitution seems like an effective means to getting needs met and the consequences of the lifestyle are not as severe, the enticement to leave would have to be met with promise of a better situation. When engaging with women in the later stages, there would be less time spent convincing her of the downside and more time ensuring that her concerns for her health and welfare will be addressed. A woman may encounter a potential service provider during any one of these developmental stages; thus, an approach that recognizes the differences in the life course of prostitution and works to maximize those aspects will facilitate a positive change.

\section{The Reality of Working in Sex Trafficking}

In addition to developmental stages, there are work style variations for women engaged in prostitution. Williamson and Baker (2009) developed these typologies through numerous interviews with women engaged in prostitution. Williamson and Baker (2009) detailed the work style typologies of women engaged in street-level prostitution, which remains one of the only resources explaining the work experiences within sex trafficking. Rand (2009) provides a description of "the life" of adolescents engaged in commercial sexual exploitation, which reflects Williamson and Baker's (2009) first work typology. The information about work types is useful to providers assisting a victim who is attempting an exit. The three categories include (1) pimp-controlled prostitution, (2) renegade prostitution, and (3) outlaw prostitution. There are differences between each category based on affiliation with others, client base, and activities not related to sex work.

Pimp-controlled prostitutes are those who were enticed, finessed, and manipulated as adolescents into working for a pimp in order to achieve a lifestyle that would help them survive. They learn quickly that they are not keeping much of what they earn (if any). Women are often assimilated as part of a pimp's "family" of prostitutes and are expected to train one another and maintain control. Expectations to reach a daily quota for money are enforced through violence and other forms of punishment and intimidation. Those wanting to quit are left with few options, other than attempting an escape (Williamson and Baker 2009). In the second typology of renegade prostitutes or independent entrepreneurs, women are working without a pimp. They are often escapees of the pimp-controlled environment and build a regular clientele. While the threat of violence from a pimp is lessened, the threat of violence from a customer is very real. Women engaged in renegade prostitution learn to carry weapons and/or hire persons to act as security or "watchers."

Williamson and Baker's (2009) third work type category describes those who participate in dishonest activities to swindle and obtain money from unsuspecting customers. These outlaws or street hustlers are targeting those who are unfamiliar with them, as they aim to walk away with more than what was agreed upon through manipulation or robbery and do not want to engage in sexual activity, if they can avoid it. The ability to rob, steal, and manipulate is a learned skill within sex trafficking. Outlaws often work with a partner, usually a boyfriend, who is instrumental in arranging "dates," providing security and being part of the overall scam. Although he is not described as a "pimp," he has a stake in the activities (Williamson and Baker 2009).

One ubiquitous feature within each work typology is violence Nixon et al. (2002). Violence is an everyday occurrence in the lives of women and girls working in sex trafficking, beginning in childhood and continuing through adolescence and adulthood (Nixon et al. 2002; Hossain et al. 2010). Violence comes from intimate partners, customers, pimps, fellow prostitutes, police officers, and other professionals (Nixon et al. 2002; Hossain et al. 2010). The violence escalates and becomes more normalized once one is engaged in sex work (Campbell et al. 2003). The result of this lifetime of violence is often desensitization. Thus, the impact of violence and its aftermath of trauma, desensitization, and dissociation must be addressed by those working with survivors.

While not all victims of sex trafficking will fit neatly into one of these three categories, it is helpful to recognize the various work styles that exist, especially as it relates to working with those emerging from this experience. For example, women who were trafficked as girls and were pimp-controlled for most of their adolescence and young adulthood may feel their work as a "renegade" or "outlaw" is an improvement. Understanding the 
Table 1 Developmental stages of prostitution (Williamson and Folaron 2003)

Developmental stages of prostitution

Enticement into the lifestyle

To enter, two preconditions are necessary: (1) enticement by the prospects of financial gain and (2) shedding of any moral objections to prostitution work

Learning the lifestyle: feeling powerful

Learning the lifestyle requires adapting to a new environment and learning the rules of behavior for success and survival. In this learning phase, the rewarding aspects of prostitution are prominent and women focus on the benefits of the lifestyle. Prostitution life is fast-paced (p. 276)

Living the lifestyle: trusting the game

The most prominent feature of this phase is the increased time spent in prostitution. Prostitutes in this phase distance themselves from conventional connections such as school, church, and other political and social institutions (p. 279)

Caught up in the lifestyle: accumulating burdens

At this phase, women are experiencing chronic depression, drug abuse, and learned helplessness. Life consists of "drug seeking and rug taking" (p. 281). Physical health deteriorates, including weight and other chronic conditions that were untreated. Their emotional state is weakened as well. As the addiction to drugs becomes more consuming, women are further immersed and further cut-off from any social supports, including children and family

Leaving the lifestyle: taking stock and getting out

The decision to exit is one that is reached through some reflection upon the ability to continue in the lifestyle. There must also be a belief that there is "something better" out there for the woman

Reentrance into the lifestyle: the loss of options

Whatever means prompt women to exit, without help and support, the most gallant tries often result in reentrance into the prostitution lifestyle following a stressful event (p. 284)
Additional context

It is likely that the woman/girl has significant needs (e.g., food and shelter) that cannot seem to be met through another resource. Prostitution is seen as a survival strategy to help alleviate financial burdens. Emotional burdens from a stressful home life, including abuse, neglect, and poverty, may impact a girl/adolescent to flee and enter the lifestyle

In this learning phase of the prostitution lifestyle, the women begin to incorporate new habits and new ways of thinking. They find a way to silence moral restraints and begin to value exploitation. The rule on the street is "Don't hate the player, hate the game." With that sentiment, women are taught to take it in stride and learn from their mistakes (p. 277); women develop protective strategies against getting arrested and against dangerous "dates"

Distinct activities of this phase include (a) increase in socialization with underground social networks, resulting in increased drug use; (b) experience with a broader range of customers; and (c) increase in more customer-related violence. Because of the increased work and increased violence, the enticement of the lifestyle is lessened. There is an increase in depression. Drug use moves from a recreational purpose to a functional purpose in order to do the work

Immediate gain becomes the goal of almost every opportunity, later provoking deep remorse and shame. Safety becomes a secondary concern as women place themselves at increased risk to obtain money to buy drugs. During this time, women accept the element of chance and the little control they have over customer-prostitute encounters. For those who enter prostitution after the onset of drug addiction, the context is slightly different during this stage. Drug-addicted women enter already "caught up" in a wave of drug addicting behaviors and drug addiction needs. In order to serve the addiction, addicts new to prostitution engage in a substantial amount of customer contact. The probability that they would employ protective strategies is slim, having never taken the initial time to enter, learn, and adjust to the mores of the lifestyle (p. 281)

It is the sum totals of daily hassles, acute traumas, and chronic conditions that precipitate a woman's decision to exit prostitution. There is some evidence that institutional pressures also have an effect on a woman's decision to leave, particularly pressures from law enforcement and child protective services. A combination of arrests, time in jail, and probation mandates put pressure on women to consider exiting the life. Outside pressure is successful when it is accompanied by a strong, personal desire to exit the life. Without a personal desire to quit, outside restrictive measures are only temporary (p. 283)

Poverty is cited as the leading factor precipitating and reentrance into the lifestyle

et al. 2008; Zimmerman et al. 2011). Substances play a unique role within the context of sex trafficking as they may make the situation easier to cope with or become the only escape available. Addiction carries its own stigma, as addicts are engaging in illegal behavior to obtain drugs and are often ashamed of their dependence upon substances. Once the victim is addicted to drugs, then she is even more dependent upon sex trafficking or the trafficker, as he or she may control the supply or access to the means to obtain drugs. Thus, the vicious cycle of addiction and sexual work is created and perpetuated.
The reality of sex trafficking is a harsh one with much collateral damage to the victim's physical, mental, emotional, and spiritual health. The development of alcohol and drug addiction is common, often beginning with forced and coerced use in childhood or adolescence (Sallmann 2010; Williamson 
In addition to the deleterious effects of substance dependence, victims often face significant health conditions that may have begun prior to their entry (Benoit and Millar 2001; Oram et al. 2012; Sabella 2011; Newby and McGuinness 2012; Zimmerman et al. 2011). These health issues likely continued to progress during their detention and exploitation and were only treated in extreme emergencies, due to lack of access to medical services and fear of being arrested or further punished by the pimp or trafficker. Healthrelated issues are numerous and include sexually transmitted diseases, HIV/AIDS, hepatitis C, malnutrition, dehydration, and fatigue (Newby and McGuinness 2012; Nixon et al. 2002). Sexual and reproductive health problems are prominent, as girls and women may have experienced multiple pregnancies, multiple unsafe (illegal) abortions, have chronic vaginal and pelvic pain, and experienced many untreated urinary tract infections (Newby and McGuinness 2012; Sabella 2011). Other chronic pain issues occur in the jaw and neck from oral sex, and the many injuries from physical violence contribute to migraine headaches and other muscular issues (Newby and McGuinness 2012; Zimmerman et al. 2011)

The prevalence of mental health disorders is high in victims of sex trafficking (Arnold et al. 2000; Hossain et al. 2010; Newby and McGuinness; Oram et al. 2012; Williamson et al. 2008). Development of trauma-related disorders such as posttraumatic stress disorder (PTSD) is often seen as a result of the exposure to abuse (Hossain et al. 2010; Twill et al. 2010; Williamson et al. 2008). The emotional trauma manifests in disorders including panic attacks, generalized anxiety, depression, suicidal ideation, and obsessive-compulsive disorder (Hossain et al. 2010; Newby and McGuiness; Williamson et al. 2008).

The progression within sex trafficking is absolutely harrowing when one considers all the difficulties endured by the victim. Their personal situations increase in complexity with each passing year, making their needs numerous. This next section examines the process of exiting, which takes into account the many challenges and needs of this population, as they relate to escaping or leaving. The individual and societal factors related to exit are discussed to inform those working to assist victims as they transition to freedom and survivorship.

\section{The Process of Exiting}

Exiting sex trafficking is an emerging topic of study in the literature. The how and why of leaving are less examined than the process of entry (Oselin 2010). The how of the exit is about strategy - literally, what steps are taken to escape and/or leave. The why of the exit is intertwined in internal and external circumstances. Both components play a role in the exit process and are the focus of this section.

\section{Barriers to Exiting}

There are multiple barriers to exiting/escaping sex trafficking. Factors that inhibit or prevent victims from seeking help are conceptualized in four categories: (1) individual, (2) relational, (3) structural, and (4) societal (Baker et al. 2010). The first two factors, individual and relational, can be thought of at the human-to-human level as they reflect the relationship with the self and the relationship with others. Individual factors are those associated with personal drive, abilities, and sense of self efficacy, which are hampered by trauma, shame, internalized stigma, substance abuse and mental illness, health issues, and lack of knowledge about resources for help (Baker et al. 2010; Oselin 2010; Wilson and Dalton 2008). Relational factors are those associated with her close relationships and informal social network (Baker et al. 2010). Strained or limited family relationships and associations with those still involved in sex trafficking may negatively impact these factors. Thus, little relational support exists for someone looking to exit; in fact, threats of violence and death for attempting to leave are likely present (Wilson and Dalton 2008).

The second two categories are on the person-to-community level and relate to one's relationship with greater society and the local community. Structural factors are those associated with societal circumstances. These include a lack of employment available to those with few marketable job skills and a criminal record, a lack of resources for basic needs (e.g., hosing, homelessness, poverty, economic self-sufficiency), an unfinished education, and a scarcity of adequate services within the community to meet these complex needs (Baker et al. 2010; Benoit and Millar 2001; Oselin 2010). Societal factors are those that capture social perceptions (i.e., discrimination and stigma) of prostituted women and likely affect, in profound ways, the other factors (Baker et al. 2010). Attitudes about male and female roles, the context of sexuality, and the concept of sexualization are contributing factors to the demand for sex trafficking and are part of this category (Nixon et al. 2002; Oselin 2010).

These barriers do not exist in isolation and cannot be addressed outside of the context of a complicated and difficult situation. The mental and emotional inner turmoil that comes with the decision to escape, quit, leave, and inevitably change one's circumstances is part of a long journey of qualitative lifestyle changes that are accompanied by obstacles at every turn (Arnold et al. 2000). Sadly, when one exits, it is not as if everything simply falls into place to ensure that she is safe, her needs are met, and that people are willing and able to help her restore and recover her life. In many communities, there is little awareness of sex trafficking, fragmented and inadequate responses for services, and few supportive resources. However, the identification of barriers alone is not enough to fully understand and assist with the process of exiting. The process itself is complicated and is discussed in the next subsection. 


\section{The Process of Exiting}

Baker et al. (2010) propose an integrated six-stage model to describe the "complex and convoluted process" of exiting prostitution (p. 579). Their model is depicted in Fig. 1 (p. 591). The details within the stages displayed in Fig. 1 are discussed, followed by implications for various community systems that may intervene with those who are exiting.

Immersion is the first stage and is the beginning of the journey and describes the indoctrination of the individual into the lifestyle by the trafficker/pimp and other associates. Immersion is part of the entry pathway as its main goal is to detain and retain the individual. This immersion leaves little room to consider leaving or even develop the awareness of leaving. Thus, during this stage, an exit would occur typically through interception - meaning a victim is discovered and forcibly removed. However, permanent exit may be difficult for someone who is in this first stage due to intense fear of being recaptured or fear of being without any resources.

Visceral awareness and conscious awareness occurs in the second stage. Visceral awareness is described as a "gut" feeling about leaving prostitution due to the awareness that things have changed. Conscious awareness is an amplification of these visceral feelings of wanting to leave. Part of consciousness is a verbalization of these feelings. Again, this stage is a difficult one to imagine a successful exit, as awareness is not enough to ensure safety or available help. Talking about wanting to leave is a dangerous proposition and could result in severe punishment.

Deliberate planning is the third stage and involves an assessment of formal and informal support resources. This

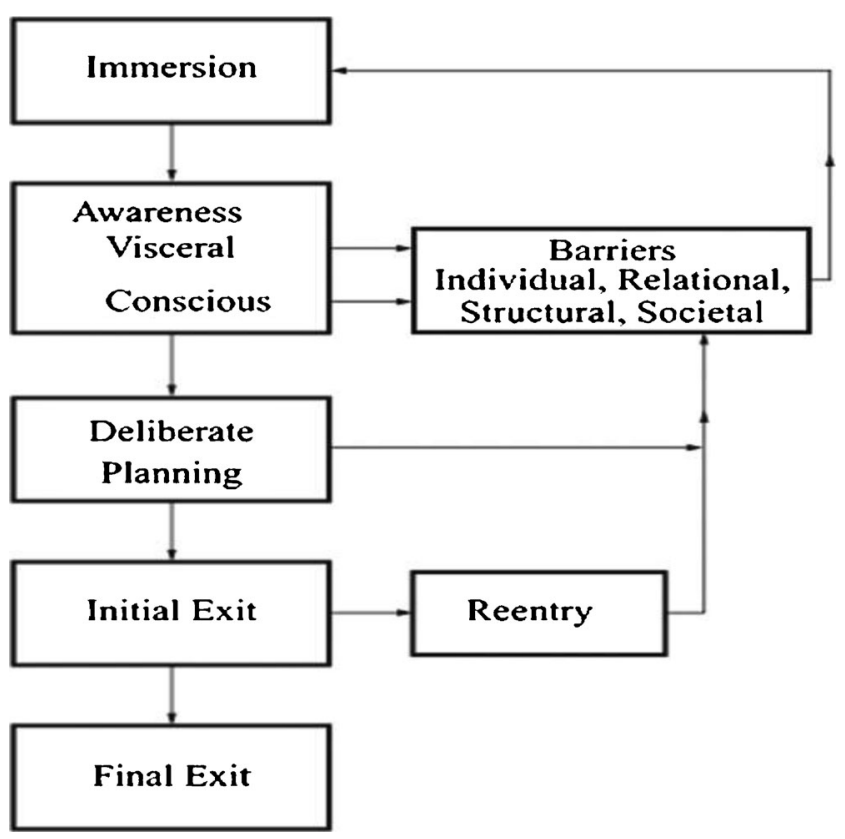

Fig. 1 Integrated model planning may be initiated by the individual or imposed by others (e.g., social services, criminal justice, family). Preparing to exit is, again, a very dangerous move and one that should be approached with significant attention paid to safety for the individual. Initial exit is the fourth stage. Baker et al. (2010) explains the complex and delicate nature of this stage as cyclical due to the reality of reentering soon after an initial exit. Baker et al. (2010) emphasize the importance of the work done in the deliberate planning stage, as it lays the foundation for a successful exit process. During this stage, formal services and informal supports are essential to ensure that the individual's needs are met and that she does not feel the draw to return to her former situation to survive. Professionals working with the woman at this time should be aware that service provision is predicated on service receptivity, and in these early stages, her sense of safety, confidence, and motivation is regularly tested (Baker et al. 2010).

Reentry is the fifth stage in this model and captures the reality of the exit process. Reentry into sex trafficking may result in a complete reimmersion into the industry/lifestyle despite conscious awareness of a need to change. The individual may be faced with the barriers discussed in the previous section, which prevent her from being successful in her exit from sex trafficking. It is quite possible that reentry functions much like a relapse process in addiction and may be part of the journey toward final exit. Final exit is the sixth stage and the most complicated to define, as it often occurs after a series of cycling in and out of prostitution. Final exit relies on one fining legal employment, safe residence, persons supportive of this "new lifestyle," and many other factors (Baker et al. 2010). Because these factors are volatile, reentry is always a possibility, even after significant time away.

This integrated model explains the complexity of exiting and highlights reality that leaving is more than a simple decision to go. Rather, numerous variables (both internal and external) can impact the ability of the person to successfully exit and not reenter. Resources available within the community, combined with the societal factors that contribute to support, awareness, and compassion for the victim/survivor, are essential to a successful and sustained exit. Various professionals play an important role in developing a response that is adequate to meet the needs of this population. Specific guidance for the criminal justice system and the health and social services systems is provided in the following subsections.

\section{Exiting: the Role of Law Enforcement and Criminal Justice}

Effectively combating human trafficking begins with proper identification of human trafficking cases. Thus, it is imperative that frontline responders, especially law enforcement 
agencies, are equipped with the know-how to correctly identify and respond. Various tools have been developed and disseminated to assist law enforcement officers to identify victims of human trafficking (i.e., Trafficking in Persons Reports from the US Department of State). However, the transfer of this information into direct community practice is slow (United Nations Office on Drugs and Crime 2012). Law enforcement officers can take first steps to (a) identify human trafficking victims and perpetrators, (b) stabilize and control the human trafficking situation, (c) prepare victims and pass information on to investigators, and (d) refer victims to specialized service providers (Farrell et al. 2012; United Nations Office on Drugs and Crime 2012). Prioritization and awareness raising through education and training for officers, state attorney generals, and district attorneys are a needed first step to impact this situation, followed by an improved understanding of the victim experience (versus the criminal experience); these efforts will facilitate a change in perception and response (Farrell et al. 2012).

Once they have identified victims, police, prosecutors, and victim service providers should commit to long-term support for them. Since most human trafficking prosecutions take between 1 and 2 years to complete, a corresponding longterm victim support plan will increase the number of successful prosecutions (Farrell et al. 2012). Collaboration between law enforcement, the courts, and community providers is an essential component of outreach, engagement, and retention in services. Victims may be more apt to engage in discussion about exiting and receiving services while in the custody of the courts (Arnold et al. 2000). However, once the individual is released from custody, she may be harder to engage. Her developmental stage within sex trafficking (Williamson and Folaron 2003), combined with her work typology (Williamson and Baker 2009), may signal her exit stage (Baker et al. 2010) and be a predictor of whether or not she will accept or decline the available resources. Thus, the role of health care workers and social workers cannot be overstated, nor can the relationship between these systems and the criminal justice system.
Exiting: the Role of Health Care Professionals and Social Workers

Social workers and health care providers are likely to encounter, and therefore identify early, trafficked persons in settings including emergency rooms, health clinics, child welfare, treatment centers, and shelters (Alvarez and Alessi 2012; Dovydaitis 2010; Newby and McGuinness 2012; Sabella 2011). Social workers that identify a trafficked person should recognize that the individual might not be able (nor willing) to seek help at the time of identification for fear of retaliation from the trafficker (Alvarez and Alessi 2012; Newby and McGuinness 2012; Sabella 2011). Attempting to identify victims is challenging, as most psychosocial assessments will not pick up on trafficking as a symptom per se; rather, the distinct physical and emotional symptoms will indicate a potential trafficked person.

Victims are often young (10 to 17 years of age) and are therefore experiencing forms of abuse and neglect. Therefore, child welfare agencies must be part of a community service approach (Fong and Cardoso 2010; Mitchell et al. 2010). The response of child welfare workers must also include proper identification of victims; suggestions for those working in child welfare include (a) an examination of organizational practices and polices related to child welfare assessments to appropriately capture the trauma experienced by child victims and accurately identify the treatment needed, (b) an inventory of potential partners for appropriate services for children, and (c) a thorough exploration into the family of the child to ensure that the child is not placed back into a trafficking situation (Fong and Cardoso 2010; Mitchell et al. 2010). Coordination efforts between child welfare and juvenile justice is needed, as detaining victims in a detention center is not seen as ideal (Kotrla 2010; Mitchell et al. 2010; McClanahan et al. 1999)

As social workers develop interventions for this population, they are faced with the creation of a comprehensive and multisystemic approach, due to the many needs described in earlier sections of this article. Complex needs such as these

Table 2 Immediate needs

Immediate safety

Emergency shelter

Basic necessities

Language interpretation

Emergency medical care
Survivors need to feel safe in order to recover. Removal from current physical location and placed in shelter, health care facility, halfway house, etc.

Much of the literature describes the need for safe and secure shelter as an immediate need of survivors following emancipation from trafficking (Aron et al. 2006)

Survivors should initially be offered basic necessities including food, clothing, shoes, and toiletries such as soap and feminine hygiene products (Armstrong 2008; Aron et al. 2006; ICF International 2007). Clawson and Dutch (2007) made a salient point that until these basic needs are met, survivors may be able to do little toward securing their safety, addressing their legal needs, or recovering from the trauma of their experiences

The review also revealed important considerations for effective services, including (a) speaking the survivor's native language and (b) providing culturally appropriate services

To address any medical needs that may be life threatening 
Table 3 Ongoing needs: once survivors' immediate needs have been addressed, survivors then need help in recovery from trauma to establish stability in their lives

Physical health Physical violence is the most recognized and documented feature of human trafficking perhaps because this, along with sexual violence, is the most convincing evidence of a crime. Sexual and reproductive health risks are among the most commonly reported health problems among individuals who are sexually abused and exploited, including pelvic and vaginal pain, sexually transmitted infections, and unwanted pregnancy (Dovydaitis 2010; Garcia-Moreno et al. 2006;

Leserman et al. 1998), whether or not they are forced into prostitution. Among the women in the study, over half (58 \%) reported a gynecological infection diagnosis (Zimmerman et al. 2011). Health problems seen in victims are related to factors such as deprivation of food, sleep, extreme stress, violence, and dangerous work; they are likely to receive health care only after these problems are advanced (Dovydaitis 2010)

Mental health Mental health is perhaps the most dominant health dimension in trafficking cases because of the profound psychological damage caused by (often chronic) traumatic events and the common somatic complaints that frequently translate into physical pain or dysfunction. An individual's psychological responses are very often correlated with many —if not each —of the other risk categories. For example, depression is frequently detected among those who are sexually abused, drug addicted, socially marginalized, or with insecure immigration status (Silove et al. 2006). Women trafficked for forced sex work show high levels of post-trauma reactions, including PTSD and depression; anxiety; and hostility which is associated with physical injury, trafficking conditions, (such as a longer time period and restricted freedom), and a short time period out of the trafficking situation (Hossain et al. 2010). Mental health symptoms found among these women are similar to those documented for individuals exposed to repetitive trauma or chronic abuse (Krakow et al. 2000).

Substance Substance abuse is also a serious problem for survivors. Traffickers may use substances as a method of control that in turn leads survivors to addiction. In addition, survivors may turn to substances as a way to cope with the trafficking ordeal (Arnold et al. 2000; Clawson and Dutch 2007; Raymond and Hughes 2001). Consequently, survivors may continue to misuse and abuse substances even after they are no longer trafficked. Arnold et al. (2000) found that survivors often wanted treatment programs designed specifically for prostitutes because of "the shame associated with prostitution," which makes it difficult to disclose and share in therapeutic groups (p. 124)

Sallmann (2010) adds substance use treatment programs could benefit from similarly becoming "prostitution-informed." This would require workers striving to provide services that are nonjudgmental of prostitution involvement and that convey the treatment environment is a safe place to disclose and discuss such issues. Additionally, findings point toward the importance of making prostitution-specific services available to women in substance use treatment (p. 134)

Child custody Child custody issues are ever-present with human trafficking. Children and adolescents involved in trafficking need safe homes to return to; women involved with trafficking may have children of which they have lost parental rights

Vocational Persons who are trafficked will need assistance with educational and vocational needs, especially as they impact self-sufficiency and needs deter the return to the streets to survive (Arnold et al. 2000)

may not have suitable interventions available in many communities, making a referral to appropriate care quite challenging. Yet, finding appropriate care is essential to a successful exit process for trafficked persons. The importance of enhancing services to ensure the needs of this population are met represents a call to action for policy and practice in social services. The next section describes services for victims/ survivors of trafficking that address their complex needs.

Table 4 Long-term needs: survivors enter a recovery phase in which they begin to establish independence and require services to address long-term needs (Macy and Johns 2011)

Life skills

Language skills

Education and job training

Permanent housing

Legal advocacy

Family reunification
Life skills training is important for a survivor's ability to secure financial independence and care for herself or himself (Armstrong 2008; Aron et al. 2006; ICF International 2007; Clawson and Dutch 2007; Tzvetkova 2002; VSSLS 2010). For example, life skills training should include information on how to use public transportation and how to manage finances. Such life skills are essential to complete rehabilitation for survivors

The review also revealed important considerations for effective services, speaking the survivor's native language and providing culturally appropriate services

Given that most survivors have worked solely in the sex industry, they need life skills and job skills training to secure and sustain employment

The literature also describes secure shelter as a short-term need of survivors, which shifts to a long-term need for permanent housing as survivors work to rebuild their lives

Several documents emphasized the importance of providers contacting a legal representative when a client is identified as a sex trafficking survivor (i.e., and has not already secured legal representation). This action will ensure that the confidentiality privileges that exist between survivor and legal counsel are in place before the survivor discloses any information that might affect his or her legal or immigration status

Family reunification may be important service goals for some survivors; such goals may place many survivors at serious risk of retrafficking and other adverse consequences 
Table 5 Addressing the internal wounds: the psychological aftermath of human trafficking (2012 Trafficking in Persons Report, US Department of State)

Steps to reinstating psychological well-being include (p. 12)

- Establishing a dependable safety network for victims to utilize and ensuring all their basic needs are met;

- Ensuring privacy and confidentiality to protect victims and their families and friends;

- Soliciting the support of medical experts, social workers, and psychologists who are trained in human trafficking and can provide trauma-specific therapy;

- Attending to victims' physical well-being, as sometimes there are physical symptoms existing simultaneously with or indicative of underlying psychological disorders;

- Providing collaborative therapies that are culturally sensitive;

- Fostering an empowering environment in which victims actively participate as consumers of therapeutic and other services;

- Assessing victims for self-injurious and suicidal behavior;

- Screening for post-traumatic stress disorder (PTSD), substance abuse/ dependence, depression, and anxiety - mental disorders that can develop as a result of being trafficked;

- Providing unconditional support, especially amidst victims' potential denial, distrust, reticence, shame, or anger;

- Working toward social and familial reintegration;

- Rebuilding identity; and

- Reestablishing skill-sets, self-esteem, and personal interests

\section{Services for Trafficking Survivors}

Learning the indicators of persons who are involved in sex trafficking is essential. The first group of indicators can be considered as suspicious circumstances for teens and may include teens accompanied by a much older man, lying about one's age or providing false identification, missing a lot of school, chronic running away, prior involvement in foster care or protective custody, having a cell phone that is not paid for by a parent or guardian, and having access to a hotel key (Fedina et al. 2008; Sabella 2011). The second group of indicators can be considered red flags for potential sex trafficking and may include restricted or strict communication, inconsistencies in one's story, exhaustion, fear, anxiety, panic or depression, recurrent sexually transmitted infections, recurrent urinary tract infections, multiple pregnancy tests, bruising and injury, bald patches of missing hair, tattoos on neck or other visible places (branding), and substance abuse/addiction problems (Fedina et al. 2008; Sabella 2011).

Once a victim is identified, the next task is the attempt to engage her in assistance. It is at this point in the intervention that one must be aware of what services actually exist within the community, as well as the inherent risks involved to the victim as she attempts to leave. Whether the victim/survivor is a youth or an adult, there are numerous needs to be addressed, including safe and appropriate housing, physical and mental health care, legal services, child custody/welfare, and basic needs like food and clothing (Clawson and Dutch 2007; Kotrla 2010). Interventions that target these interconnected needs require community collaboration and a specialized focus on prostitution (Arnold et al. 2000). Clawson and Dutch (2007) categorize needs as emergency/safety, then short-term, and long-term. These needs are described in Table 2.

Williamson and Folaron (2003) remind social workers that contact with women involved in sex trafficking happens within several systems: criminal justice, child protection, hospital, and addiction treatment. Reaching them and working to help them exit or assist with "rescue and restore" involve strategies for prevention and intervention. Thus, an approach that includes multiple services within programs is recommended (Kotrla 2010). Table 3 describes these ongoing needs; Table 4 describes long-term needs.

Trauma and the need for treatment cannot be emphasized enough when designing services for victims/survivors of

Table 6 Intervention strategies based on prostitution typology (Williamson and Baker 2009)

Outlaw prostitution

Those who participate in dishonest activities (hustling) to swindle and obtain money from unsuspecting customers. Outlaws typically hope to walk away with more than what was agreed upon through manipulation or robbery and do not want to engage in sexual activity, if they can avoid it. Unique to this category of workers is a relationship with a partner

Pimp-controlled prostitution

Those who were enticed, finessed, and manipulated as adolescents into working for a pimp in order to achieve a lifestyle that would help them survive

\section{Renegade prostitution}

Those who work without a pimp. They enter street-based prostitution as free agents or escape the grasp of a pimp to become free agents. Women engaged in renegade prostitution learn to carry weapons and/or hire persons to act as security or "watchers" to deal with threat of violence from customers
Social workers should be aware of the danger involved in "hustling behavior" which places "outlaws" at an increased risk for violence. They may also need more legal assistance because of criminal charges. The relationship with the partner who was involved with the "hustling" will need to be addressed as well

Because of the coercive and controlling nature of pimps, leaving prostitution may be a different experience, requiring quicker and more comprehensive planning. Ensuring a woman's safety from the pimp is an immediate concern. Women who have been controlled by pimps may require additional treatment to address the physical, psychological, and emotional aftermath of this traumatic relationship

The renegade prostitute woman may want to negotiate her care or the services she receives rather than having them imposed by social workers because she is used to a business-oriented, independent work style 
human trafficking, as trauma issues are a lead contributor to reentry and revictimization (US Department of State 2012). Common responses to trauma and victimization include physical and emotional reactions, all of which are easily attributed to other problems, making proper assessment of trauma essential. Physical reactions include a weakened physical state; bruises, cuts, or other untreated medical ailments; and complaints of stomach pain, heart palpitations, and extreme changes in eating patterns (US Department of State 2012, p. 17). Emotional reactions can include loss of memory related to the traumatic event, frequent bouts of tearfulness, detachment, feelings of self-blame, emotional numbing or emotional response that does not fit the situation, flashbacks or nightmares, anxiety and fear, difficulty making decisions and/or concentrating, and avoidance of eye contact in a manner not related to culture (US Department of State 2012 p. 17). Table 5 provides a list of steps to address the aftermath of trauma.

Williamson and Baker (2009, p. 42) suggest social workers base their intervention strategies on understanding the prostitution work typologies. A service continuum is one aspect of the intervention; the strategy or approach to providing the services is equally as important. Intervention strategies based on work typology are depicted in Table 6.

Thus, service needs and intervention strategies require an approach that is comprehensive and multisystemic. Approaches that engage providers across systems (housing, health, child welfare, addiction, mental health, vocational assistance) require changes and the policy and institutional level in order for services to be delivered in a coordinated manner. The next section provides considerations for policy and system changes.

\section{Summary}

Sex trafficking is a form of human trafficking that is widespread across the globe. It has a negative impact upon society, as human beings are sold, traded, and stolen into this form of slavery. As communities across the world attempt to address this problem, knowledge about the process of sex trafficking is important - from the factors that place a person at risk to the pathways of entry, the progressing within sex trafficking, and the process of exit. This focus on process provides a context for prevention and intervention. Preventing sex trafficking begins with a decrease in risk factors, namely, the sexual and physical abuse of children, which places them at risk to run away or run to the promises of a trafficker. Successful intervention strategies are predicated on an understanding of the progression within the sex trafficking world and how it changes an individual's development. The indoctrination, the constant and pervasive trauma, and the comorbid development of physical and mental health issues complicate the entrapment of the victim. The ability to exit is often dependent on a series of factors within the individual and within the community being present. A comprehensive and multisystem approach is needed for an effective intervention. However, this approach needs to have a perspective that is centered on the experience of the sex trafficking victim at the core of its work. The reality of the exit process, which is dangerous and difficult, emphasizes the need for an approach that is also longterm. Victims may vacillate between remaining within sex trafficking and exiting, as the process of change is unstable and frightening. Detailed planning for immediate and long-term needs with the victim/survivor will assist her in feeling more prepared and secure about her transition. This approach cannot rest on the work of one provider; rather, it requires a commitment of the community and the collaboration of professionals between systems. Communities can benefit from the work already being done in many countries, states, and territories. The more information that is shared about efforts to address this important issue, the better equipped we become as professionals to address the needs of this population.

\section{References}

Alvarez, M. B., \& Alessi, E. J. (2012). Human trafficking is more than sex trafficking and prostitution: implications for social work. Affilia Journal of Women and Social Work, 27(2), 142-152.

Armstrong, H. C. (2008). Rebuilding Lives: an introduction to the promising practices in the rehabilitation of freed slaves. Retrieved from https://www.freetheslaves.net/sslpage. $a s p x$ ?pid=362.

Arnold, E. M., Stewart, J. C., \& McNeece, C. A. (2000). The psychosocial treatment needs of street-walking prostitutes: perspectives from a case management program. Journal of Offender Rehabilitation, 30(3/4), 117-132.

Aron, L. Y., Zweig, J. M., \& Newmark, L. C. (2006). Comprehensive services for survivors of human trafficking: findings from clients in three communities. Urban Institute: Justice Policy Center. Retrieved from http://www.urban.org/UploadedPDF/411507_human_ trafficking.pdf.

Baker, L. M., Dalla, R. L., \& Williamson, C. (2010). Exiting prostitution: an integrated model. Violence Against Women, 16(5), 579-600.

Benoit, C., \& Millar, A. (2001). Dispelling myths and understanding realities: working conditions, health status, and exiting experiences of sex workers. Victoria, Canada: Prostitutes Empowerment, Education and Resource Society.

Campbell, R., Ahrens, C., Sefl, T., \& Clark, M. L. (2003). The relationship between adult sexual assault and prostitution: an exploratory analysis. Violence and Victims, 18(3), 299-317.

Clawson, H.J., \& Dutch, N. (2007). Addressing the needs of victims of human trafficking: challenges, barriers and promising practices. Issue Brief; US Department of Health and Human Services, Office of the Assistant Secretary for Planning and Evaluation. Retrieved from www.aspe.hhs.gov/hsp/07/HumanTrafficking.

Dovydaitis, T. (2010). Human trafficking: the role of the health care provider. Journal of Midwifery and Women's Health, 55, 462-467.

Farrell, A., McDevitt, J., Pfeffer, R., Fahy, S., Owens, C., Dank, M., Adams, W. (2012). "Identifying challenges to improve the prosecution of state and local human trafficking cases, 
executive summary". Grant award (2009-IJ-CX-0015). Retrieved from: www.urban.org.

Fedina, L., Trease, J., \& Williamson, C. (2008). Human trafficking in Ohio: a resource guide for social service providers. Retrieved from http://secondchancetoledo.org/secondchance/resources.

Fong, R., \& Cardoso, J. B. (2010). Child human trafficking victims: challenges for the child welfare system. Evaluation and Program Planning, 33, 311-316.

Garcia-Moreno, C., Jansen, H., Ellsberg, M., Heise, L., \& Watts, C.H. (2006). Prevalence of intimate partner violence: findings from the WHO multi-country study on women's health and domestic violence. Lancet, 368, 1260-1269.

Hossain, M., Zimmerman, C., Abas, M., Light, M., \& Watts, C. (2010). The relationship of trauma to mental disorders among trafficked and sexually exploited girls and women. American Journal of Public Health, 100(12), 2442-2449.

ICF International (formerly Caliber Associates). (2007). Evaluations of comprehensive services for survivors of human trafficking: key comprehensive services for survivors of human trafficking: findings from clients in three communities findings and lessons learned. U.S. Department of Justice. Retrieved from https://www.ncjrs.gov/App/ Publications/abstract.aspx?ID=240518.

Kotrla, K. (2010). Domestic minor sex trafficking in the United States. Social Work, 55(2), 181-187.

Krakow, B., Artar, A., Warner, T. D., Melendrez, D., Johnston, L., Hollifield, M., Germain, A., \& Koss, M. (2000). Sleep disorder, depression, and suicidality in emale sexual assault survivors. Crisis: The Journal of Crisis Intervention and Suicide Prevention, 21(4), $163-170$.

Kramer, L. A., \& Berg, E. C. (2003). A survival analysis of timing of entry into prostitution: the differential impact of race, educational level, and childhood/adolescent risk factors. Sociological Inquiry, 73(4), 511-528.

Leserman, J. L., Drossman, D. A., \& Hu, Y. J. B. (1998). Selected symptoms associated with sexual and physical abuse history among female patients with gastrointestinal disorders: the impact of subsequent health care visits. Psychological Medicine, 28(2), 417-425.

Macy, R. J., \& Johns, N. (2011). Aftercare services for international sex trafficking survivors: informing U.S. service and program development in an emerging practice area. Trauma, Violence \& Abuse, 12(2), 87-98

McClanahan, S. F., McClelland, G. M., Abram, K. M., \& Teplin, L. A. (1999). Pathways into prostitution among female jail detainees and their implications for mental health services. Psychiatric Services, 50(12), 1606-1613.

Mitchell, K. J., Finkelhor, D., \& Wolak, J. (2010). Conceptualizing juvenile prostitution as child maltreatment: findings from the national juvenile prostitution study. Child Maltreatment, 15(1), 18-36.

Nadon, S. M., Koverola, C., \& Schludermann, E. H. (1998). Antecedents to prostitution: childhood victimization. Journal of Interpersonal Violence, 13(2), 206-221.

Newby, A., \& McGuinness, T. M. (2012). Human trafficking: what psychiatric nurses should know to help children and adolescents. Journal of Psychosocial Nursing, 50(4), 21-24.

Nixon, K., Tutty, L., Downe, P., Gorkoff, K., \& Ursel, J. (2002). The everyday occurrence: violence in the lives of girls exploited through prostitution. Violence Against Women, 8(9), 1016-1043.

Ohio Trafficking in Persons Study Commission, Research and Analysis Sub-Committee (2010). Report on the prevalence of human trafficking in Ohio. Retrieved from www.centralohiorescueandrestore.org.

Oram, S., Stöckl, H., Busza, J., Howard, L. M., \& Zimmerman, C. (2012). Prevalence and risk of violence and the physical, mental, and sexual health problems associated with human trafficking: systematic review. PLOS Medicine, 9(5), 1-13.
Oselin, S. S. (2010). Weighing the consequences of a deviant career: factors leading to an exit from prostitution. Sociological Perspectives, 53(4), 527-550.

Rand, A. (2009). It can't happen in my backyard: the commercial sexual exploitation of girls in the United States. Children and Youth Services, 31, 138-156.

Reid, J. A. (2012). Exploratory review of route-specific, gendered, and age-graded dynamics of exploitation: applying life course theory to victimization in sex trafficking in North America. Aggression and Violent Behavior, 17, 257-271.

Sabella, D. (2011). The role of the nurse in combating human trafficking. American Journal of Nursing, 111(2), 28-37.

Sallmann, J. (2010). "Going hand-in-hand': connections between women's prostitution and substance use. Journal of Social Work Practice in the Addictions, 10(2), 115-138.

Stansky, M. \& Finkelhor, D. (2008). How many juveniles are involved in prostitution in the US? Crimes Against Children Research Center Fact Sheet. Retrieved from www.unh.edu/ccrc.

Twill, S. E., Green, D. M., \& Traylor, A. (2010). A descriptive study on sexually exploited children in residential treatment. Child \& Youth Care Forum, 39, 187-199.

U.S. Department of State (2008). Trafficking in Persons Report. Ambassador Mark P. Lagon (lead author), Secretary of State Condaleeza Rick. Retrieved from www.state.gov/documents/ organization/105501.pdf.

U.S. Department of State (2012). Trafficking in Persons Report, Ambassador Luis CdeBaca (lead author), Secretary of State Hillary Rodham Clinton. Retrieved from http://www.state.gov/ documents/organization/192587.pdf.

United Nations Office on Drugs and Crime: human trafficking first aid kit for law enforcement agencies. http://www.unodc.org/unodc/en/ human-trafficking/2011/first-aid-kit.html.

Victim Services and Safe Locations Sub-Committee (2010). Report to Attorney General Richard Cordray: recommendations for increasing Ohio's capacity to serve victims of human trafficking. Retrieved from http://www.ohioattorneygeneral.gov/ TraffickingVictimServices.

Williamson, C., \& Baker, L. M. (2009). Women in street-based prostitution: a typology of their work styles. Qualitative Social Work, 8(1), 27-44.

Williamson, C., \& Folaron, G. (2003). Understanding the experiences of street level prostitutes. Qualitative Social Work, 2(3), 271-287.

Williamson, C., \& Prior, M. (2009). Domestic minor sex trafficking: a network of underground players in the Midwest. Journal of Child and Adolescent Trauma, 2(1), 46-61.

Williamson, E., Dutch, N., \& Clawson, H.C. (2008). Evidence-based mental health treatment for victims of human trafficking. National symposium on the health needs of human trafficking victims: postsymposium brief. Washington, DC: Office of the Assistant Secretary for Planning and Evaluation, U.S. Department of Health and Human Services.

Williamson, C., Perdue, T., Belton, L., Burns, O. (2012). Domestic sex trafficking in Ohio: research and analysis Sub-committee, Ohio Human Trafficking Commission. Retrieved from https://www. ohioattorneygeneral.gov/Files/Publications/Publications-for-LawEnforcement/Human-Trafficking-Reports/2012-Domestic-SexTrafficking-in-Ohio-Report.

Wilson, J. M., \& Dalton, E. (2008). Human trafficking in the heartland: variation in law enforcement awareness and response. Journal of Contemporary Criminal Justice, 24(3), 296-313.

Zimmerman, C., Hossain, M., \& Watts, C. (2011). Human trafficking and health: a conceptual model to inform policy, intervention and research. Social Science \& Medicine, 73, 327-335. 